\title{
FICÇÃO CIENTÍFICA ENCONTRA O PÓS- MODERNISMO: SLIPSTREAM
}

Valéria Sabrina Pereira*

RESUMO: Em 1989, ao observar o crescente número de romances de autores aclamados pela crítica literária que apresentavam temáticas típicas de ficção científica, o escritor Bruce Sterling levantou a hipótese de que um novo gênero estaria nascendo, o qual denominou como slipstream. Um quarto de século depois, o termo é recorrentemente empregado por leitores de ficção científica, todavia, sem que houvesse se chegado a uma definição clara das características que determinam o suposto novo gênero. Este artigo discute se é realmente necessário falar de um novo gênero, e aborda os problemas da teoria da ficcão cientisăo parcialmente responsáveis pela impossibilidade de um diálogo junto aos teóricos das outras áreas da literatura.

Palavras-chave: ficção científica; slipstream; pós-modernismo.
* valeriasabrinap@gmail.com

作 USP.

ABSTRACT: In 1989, after observing the increasing number of novels written by authors acclaimed by the critics that presented typical features of science fiction, the author Bruce Sterling came up with the hypothesis of a new literary gender, which he called "slipstream". A quarter of a century later, the term has spread amongst readers of science fiction however without having settled a clear definition of the characteristics that should determine the supposed new gender. This article discusses if the definition of a new genre really is necessary, and presents are partly responsible for the impossibility of a dialogue within the academia.

Keywords: science fiction; slipstream; post-modernism. 
1. Apud STERLING. Slipstream (Todas as traduções são de minha autoria.)

2. Sterling. Slipstream.

\section{INTRODUÇÃO}

Em 1989, Bruce Sterling escreveu um breve ensaio para a revista SF Eye intitulado "Slipstream", onde defendia que um novo gênero que carregava características da ficção científica (FC) estava surgindo. O texto de Sterling foi inspirado por uma entrevista com o autor Carter Scholz, na qual ele apontava a baixa qualidade dos lançamentos recentes de FC, e dizia que o gênero havia perdido a possibilidade de se tornar literatura de qualidade porque autores não especializados em FC já estavam fazendo uso das mesmas temáticas que eles, ou, como foi colocado, "fazendo o nosso trabalho". ${ }^{1}$ Sterling acreditou reconhecer nas queixas de Scholz indícios do que ele acreditava ser um novo gênero e desenvolveu seu argumento tendo em vista autores que escreviam sobre temáticas caras à FC, mas não eram especializados nesse tipo de escrita, como Margaret Atwood (O diário da aia) e Don DeLillo (Ruído branco). O novo gênero, denominado de "slipstream", seria definido por "um tipo de escrita que simplesmente faz com que você se sinta muito estranho; do jeito que viver no final do século XX faz com que você se sinta, se você é uma pessoa de uma certa sensibilidade". ${ }^{2} \mathrm{Ou}$, em uma descrição mais breve, o slipstream seria composto por "romances de sensibilidade pós-moderna". O ensaio de Sterling é encerrado com uma longa e difusa lista de obras que poderiam ser definidas como slipstream, partindo do princípio de que exemplos seriam mais bem sucedidos do que explicações teóricas.
Sua proposta encontrou um ponto de interesse entre os leitores de FC e fantasia. Até a atualidade, mais de 25 anos após a publicação do texto, não se chegou a nenhum consenso sobre o que seria o slipstream, mas a designação ainda é amplamente aplicada por grupos de leitores de FC, tendo sua lista de publicações no site Goodreads, por exemplo. Neste artigo, será apresentada a discussão sobre o suposto gênero e observado como os fãs compreendem obras que abordam temáticas futurísticas, mas que são produzidas por autores que não pertencem ao ciclo especializado da FC (uma das possíveis definições do slipstream).

\section{HISTÓRIA DA FC E DE SEU ESTUDO}

Para compreender a problemática que originou o termo slipstream, é necessário um breve excurso pela história da FC. Uma das principais teorias correntes, defendida, entre outros, por Brian W. Aldiss, ${ }^{3}$ é que a FC teria sido iniciada em 1818, com a publicação de Frankenstein de Mary Shelley, mas só teria começado a se desenvolver de fato cerca de meio século depois, com Jules Verne e H.G. Wells. Entretanto, a FC como a conhecemos hoje é fruto do estilo que se desenvolveu nas revistas pulp, em especial na série "Amazing stories”, lançada por Hugo Gernsback, em 1926. Foi Gernsback que cunhou o termo scientifiction, posteriormente simplificado para science fiction, para nomear as histórias que publicava. Muitos dos principais nomes da FC, de Isaac Asimov
3. Aldiss: Wingrove. On the origin of species: Mary Shelley.

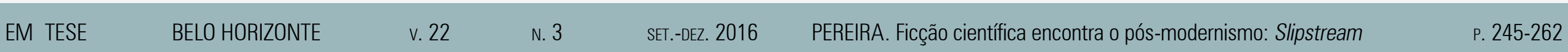

\section{Crítica Literária, outras Artes e Mídias}


a Ursula Le Guin, se formaram tanto como leitores quanto como escritores dentro do meio pulp. Se, por um lado, a seleção de textos feita por essas revistas influenciou na formação de novos escritores e ajudou a definir os contornos do gênero, por outro, a seção de cartas serviu ao estabelecimento de uma sólida rede de fãs que acabou se tornando um grupo hermético, com pouco contato com outros tipos de literatura.

O "desabrochar" da FC no meio pulp fez com que o gênero acabasse marcado como uma produção de baixa qualidade, apesar de posteriormente muitos de seus autores terem se tornado independentes desse tipo de publicação. A ruptura qualitativa se deu no final dos anos 1930, quando foi iniciada a chamada Era de Ouro, fase na qual autores como Isaac Asimov, Arthur C. Clarke e Robert Heinlein estabelecem um novo nível dentro da FC. Nessa época, ocorreu o distanciamento da literatura trivial, e uma relevante parcela de obras de FC se tornaram mais complexas. Um exemplo é o conjunto de contos escritos por Asimov na década de 1940 que posteriormente foi no livro $E u, R o b o ̂$ (1950), onde o autor desenvolveu as famosas Leis da Robótica, produzindo assim, ponderações mais aprofundadas sobre os problemas da Inteligência Artificial. Outro exemplo é o conto "By his Bootstraps" (1941) de Heinlein, onde o autor brinca com os diversos paradoxos de viagem no tempo, demonstrando que a FC havia se tornado autoconsciente e que era capaz de produzir críticas a esquemas por ela incansavelmente repetidos. É indiscutível que houve aí um salto qualitativo, tanto que esses autores são lidos e publicados até a atualidade. Esse salto, contudo, não foi grande o suficiente para garantir sua aceitação pela academia, o que é visto com maus olhos pelos leitores de FC, que consideram esse descaso simples preconceito. Como contrapartida, os fãs do gênero buscaram delimitar seu espaço através da utilização do termo "mainstream" para se referir à literatura naturalista, o que ao mesmo tempo em que sinaliza a FC como uma "minoria", indica que seus fãs são diferenciados por não seguirem a "corrente" das narrativas "realistas". Essa rejeição sofrida pela FC serviu para fortalecer ainda mais a consciência de grupo de seu fandom [grupo de fãs que se dedicam a uma subcultura particular], mas também teve efeitos colaterais que perduram até hoje, em especial o autoisolamento.

Como importante gênero literário predominantemente anglófono, a FC tornou-se oficialmente matéria dos estudos acadêmicos de língua inglesa no começo da década de 1970 Fato que, inicialmente, não foi bem recebido por leitores que acreditavam que isso poderia destruir o espírito underground da FC, como menciona um de seus primeiros teóricos, James Gunn. ${ }^{4}$ As décadas de segregação fizeram com que apenas aqueles que eram parte do fandom estivessem habilitados a falar sobre o assunto, de forma que os críticos e docentes da área eram (e ainda são) basicamente fãs

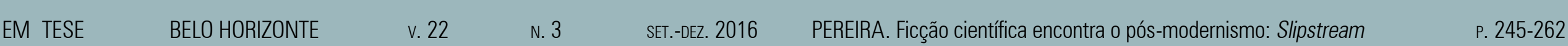


5. SUVIN. Estrangement and cognition, p. 25 e escritores de FC. Se, por um lado, críticos como Darko Suvin buscaram traçar uma relação com o restante da literatura através de elos com o cânone, como, por exemplo, Brecht - como será explicitado mais adiante -, por outro, a discussão sobre o gênero ficou majoritariamente limitada às teorias desenvolvidas pelos próprios fãs, o que fez com que deslizes não fossem corrigidos, mas metodicamente repetidos, e o diálogo com teóricos de fora desse círculo nunca tenha sido propriamente estabelecido.

A definição dominante de FC foi desenvolvida por Suvin. Para ele, as narrativas de FC são reconhecidas pelo que ele denomina como "estranhamento cognitivo" (cognitive estran gement). Em busca de inserir a FC no contexto das obras literárias bem aceitas pela academia, Suvin buscou enraizar a FC em teorias que pertenciam a esse meio. Assim, o fator científico-ficcional das narrativas de FC (ou seja, elementos contrafáticos futuristas ou baseados em hipóteses científicas e tecnológicas) tornou-se "estranhamento", um termo que se refere tanto aos formalistas russos quando a Brecht. Suvin explica que este é o conceito desenvolvido por Viktor Chklovsky para tratar de textos não-naturalistas ${ }^{5}$ (ostranenie). E posteriormente acrescenta que a terminologia também estaria ligada ao conceito de estranhamento de Bertolt Brecht, dramaturgo que, segundo ele, estaria relacionado à FC por ter afirmado que sua intenção era escrever peças para uma "era científica”. Infelizmente, em ambos os casos, há uma limitação da significação primordial. O estranhamento proposto por Chklovsky tem o intuito de obscurecer a forma, aumentando a dificuldade e a duração da percepção. Entre os exemplos dados por Chklovsky estão a utilização de pontos de vista inusitados, como a história de família narrada a partir da perspectiva de um cavalo, e a utilização da linguagem poética, independente de um efeito "naturalista" ou não. Já no caso de Brecht, Suvin foca especificamente no exemplo da peça $A$ vida de Galileo, que tem uma temática científica, mas não relaciona a FC com o conceito de efeito de estranhamento de Brecht, ou seja, o efeito de destruir a ilusão do público, criando um distanciamento que os lembra de que o que está sendo apresentado não passa de uma obra de teatro. Apesar de admitir posteriormente que o efeito de estranhamento é utilizado por Brecht em um contexto predominantemente "realista", Suvin não deixa de afirmar que o "[e]stranhamento diferencia a FC do mainstream literário 'realista”. ${ }^{6}$ Aqui fica evidente que Suvin se afasta do sentido aplicado inicialmente por Brecht e confere um novo significado ao conceito de "estranhamento", transformando-o em um sinônimo de "não realista". Marxista, Suvin defende que os elementos "estranhos", ou científico-ficcionais, servem para que o leitor questione o mundo onde vive, mas, na prática, sua teoria foca apenas o aspecto não realista da FC.

Já o adjetivo "cognitivo" serve, entre outros, para diferenciar a FC de outros gêneros fantásticos, como contos-de-fada
6. Suvin. Estrangement and cognition, p. 27
EM TESE
BELO HORIZONTE
v. 22
N. 3
SET.-DEZ. 2016
PEREIRA. Ficção cientifica encontra o pós-modernismo: Slipstream
ค. 245-262

Crítica Literária, outras Artes e Mídias 
7. Suvin também confere ao conceito de "cognitivo" o sentido de tratar de uma literatura que é capaz de fazer com que o seu leitor pense de seu tempo. Frederic Jameson adota o conceito de FC de Suvin enfatizando inclusive esse aspecto da cognição, quando ele diferencia a FC da fantasia através do fato de que a fantasia seria uma literatura de escape e não de reflexão. Apesar de Jameson admitir que essa definição vai na mesma direção que a divisão entre cultura alta e baixa que tanto prejudicou a FC, ele não oferece uma solução para esse problema. (JAMESON. Archaeologies of the future, p. 68)

8. É verdade que em sua Introdução à literatura fantástica (1970) Tzvetan que é definida como "maravih" que éfén" explicado de uma maneira racional. mas a partir de leis que a ciência contemporânea não reconhece." (TODOROV. Introdução à literatura fantástica, p. 63). A definição feita por Todorov, contudo, tem apenas a função de diferenciar a literatura fantástica da FC. Assim, ela é breve, não dá exemplos concretos e também não se atém a exceções, como as historias alternativas ou apocalípticas.

9. JAMESON. Archaeologies of the future.

10. LUCKHURST. The Many Deaths of Science Fiction: A Polemic. ou fantasia. A acepção de "cognitivo" mais bem aceita pela crítica de FC em geral é a que entende "cognitivo" como aquilo que pode ser entendido/explicado. Assim, histórias de fantasmas são definidas por Suvin como "anticognitivas", porque vão contra as leis empíricas, e contos-de-fadas seriam apenas indiferentes a essas leis. A FC seria constituída pelo "estranhamento cognitivo" por tratar de temas que abordam a apresentação de um mundo diferente daquele no qual vivemos (estranho), mas cujas diferenças são explicadas como resultado de avanços científicos, como o desenvolvimento de tecnologia espacial avançada.

Suvin foi um dos primeiros a desenvolver uma definição da FC, ${ }^{8}$ e goza ainda hoje de boa aceitação - Frederic Jameson, ${ }^{9}$ por exemplo, faz uso de seus conceitos. É necessário, contudo, expressar que sua teoria também apresenta sérios problemas. Um deles é a tendência a excluir a literatura trivial, ${ }^{10}$ porque ela não seria capaz de levar o leitor à reflexão. Quando temos em vista obras como o conto anteriormente citado "By his Bootstraps", que dialoga justamente com essa tradição, fica claro que essa exclusão não pode ser frutífera. Além disso, seu recorte temporal é deveras extenso e chega até a Antiguidade e Gilgamesh. Dessa forma, Suvin apresenta um conjunto de obras que muitas vezes não tem qualquer relação uma com a outra, além de não ser possível definir uma linha contínua em sua leitura.
Suvin, contudo, é suficientemente proeminente para que a maior parte das discussões sobre o gênero seja feita utilizando a terminologia proposta por ele, mesmo quando os teóricos envolvidos se opõem a sua definição. Além do conceito de estranhamento, o termo "novum" também é frequentemente aplicado. "Novum" é o conceito de Suvin que define o elemento do mundo ficcional que é diferente da realidade do autor ou do leitor, e que tem encontra sua justificativa em um argumento científico; ${ }^{11}$ exemplos recorrentes de novum são a inteligência artificial e as viagens interplanetárias.

Para evitar os problemas oferecidos pela teoria de Suvin, este artigo empregará a definição de FC oferecida por Hans Edwin Friedrich: "Ficção científica é um gênero multimídia da literatura fantástica, cujas ficções contém um novum incompatível com a realidade que é (pseudo)cientificamente justificado. Comumente a ação ocorre no futuro."12 Friedrich também delimita o gênero historicamente: a FC teria nascido com Jules Verne e H.G. Wells e apenas poderia ser verificada a partir de meados do séc. XIX. ${ }^{13}$

Por mais simples que esse tipo de definição possa ser, ela parece ser insuficiente por não abordar aspectos da FC enquanto "literatura de gênero", ${ }^{14}$ ou seja, um gênero da literatura popular que se orienta por processos pré-concebidos de produção, distribuição e recepção. Como Eggo Müller
11. Suvin. Metamorphoses of Science Fiction, p.64.

12. FRIEDRICH. Science-Fiction, p. 672 .

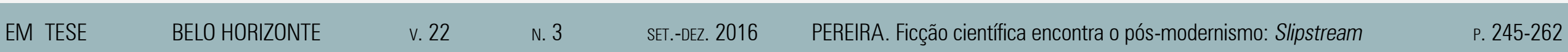

14. A expressão "literatura de gênero", que se refere exclusivamente à literatura popular, virá sempre entre aspas como forma de salientar que não se trata do conceito de gênero literário, empregado à literatura em geral. 
aponta, o processo de criação da "literatura de gênero" segue estruturas e padrões pré-estabelecidos que correspondem às expectativas dos seus leitores e isso faz com que o mercado e números de venda sejam previsíveis para distribuidores especializados. ${ }^{15}$ Embora a FC não siga padrões tão rígidos quanto romances policiais e aventuras, e tenha mais liberdade no desenvolvimento de enredos, a maioria dos seus autores está inseridas em um típico sistema de "literatura de gênero": são publicados por editoras ou revistas especializadas, que produzem capas com ilustrações que facilitam o reconhecimento do gênero da obra, de forma a alcançar com maior facilidade os fãs do gênero, que têm a sua própria lista de demandas sobre como uma obra de FC deveria ser - frequentemente uma história que preze pela descrição de novidades tecnológicas e apresente o futuro (ou o espaço) com grande detalhamento sobre como ele se diferenciaria da nossa realidade.

A FC não se limita à "literatura de gênero", mas uma vez que a maior parte da sua produção se concentra nesse esquema editorial, essas características acabam sendo reproduzidas no discurso acadêmico. Um exemplo disso é que não é incomum que a FC seja definida em termos circulares como o faz Damon Knight, "ficção científica é aquilo que apontamos quando dizemos isso", ou Norman Spinrad, "ficção científica é qualquer coisa que seja publicada como ficção científica". ${ }^{16}$ Ou a recusa de Tom Shippey de definir o gênero porque seus fãs não têm dificuldade em encontrar e comprar os livros, e mesmo aqueles que não o apreciam conseguem facilmente reconhecê-los. ${ }^{17} \mathrm{O}$ que eles não notam é que esse discurso não diz tanto respeito ao conteúdo, quanto aos marcadores editoriais, como o layout da capa, se o livro foi lançado por uma editora especializada, ou mesmo a sua localização dentro de uma livraria. Mas apenas o marketing editorial não é suficiente para caracterizar essas obras, uma vez que há claras dificuldades no reconhecimento de uma obra de FC quando ela não é publicada em seus canais típicos.

Um caso claro de disputa é 1984 de George Orwell. Erik Rabkin afirma que, entre as diferentes formas de classificar a FC, haveria o que ele chama de classificação "social", ou seja, definir a obra como FC ou não de acordo com um julgamento de qualidade literária. Segundo a tal definição "social", 1984 não seria FC "porque é bom"18 - aqui em uma classificação de qualidade que seria advinda de críticos literários não ligados à FC. Por outro lado, Robert Conquest acusa "literatos" de ignorar o aspecto científico da FC e utiliza seu artigo "Science fiction and literature" para rebaixar livros que ele crê que não são bons o suficiente para serem classificados como "ficção científica de verdade" - aqui a qualidade das obras estaria sendo julgada de acordo com o nível de inventividade, ou de informações novas. Sobre o livro de Orwell, ele afirma, "1984 precisa de toda a sua força para carregar
17. SHIPPEY. Learning to read science fiction, p. 1-3.

8. RABKIN. Defining science fiction p. 20
16. Apud ROBERTS. Science fiction, p. 2.

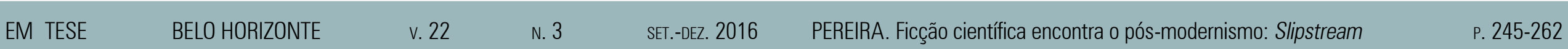


19. CONOUEST. Science fiction and literature, p. 41.

20. CONQUEST. Science fiction and literature, p. 33.

21. SAWYER. Kazuo Ishiguro's Never let me go and "outsider science fiction", p. 238. uma carga bem pequena de madeira morta". ${ }^{19}$ Conquest também se declara avesso à figura de Ray Bradbury, que só teria sido aceito pela crítica por não ser FC o suficiente, e o chama de "escritor de ficção científica para pessoas que não gostam de ficção científica de verdade".$^{20}$ Esse tipo de rejeição a determinadas obras não ocorre apenas em textos mais antigos como o de Conquest. Em um artigo sobre Kazuo Ishiguro publicado em 2011, Andy Sawyer classifica Não me abandone jamais, um romance sobre clones humanos, como "outsider science fiction" ("ficção científica de intrusos", em uma tradução livre), e ainda chega a afirmar:

O aparecimento desses artifícios na literatura mainstream ocorre provavelmente porque os autores de literatura se voltam inocentemente a temas e ideias achando que elas são novas, sem se dar conta de que elas têm sido utilizadas no campo de ficção científica há décadas. Mas as imagens da ficção científica são, agora, parte de um estoque comum de emblemas literários reconhecíveis. ${ }^{21}$

Não me abandone jamais, um dos livros citados por Rabkin ao falar da classificação "social" de FC, é uma história de amor publicada em 2005 que se passa na Inglaterra dos 1970 aos 1990. Apesar de poder ser definida como FC devido a seus protagonistas serem clones, Ishiguro produziu um livro introspectivo, sem quaisquer elementos de aventura ou a atmosfera tipicamente caracterizada como FC. Ao definir a obra como "outsider", Sawyer não apenas reivindica as temáticas científicas especulativas, ou seja, o novum para a FC, como se o uso por outras áreas fosse uma espécie de empréstimo ou furto, mas também delimita a FC àqueles que se dedicam exclusivamente a ela. De maneira inconsciente, Sawyer faz um recorte da FC que a limita à produção de "literatura de gênero" e funciona como um indício de que a "verdadeira" FC, que alguns fãs reivindicam, seria mesmo uma literatura de menor qualidade, que deve seguir esquemas, onde as invenções futuristas teriam obrigatoriamente um valor superior à profundidade das personagens.

Se, por um lado, alguns como Conquest defendem enredos cheios de desenvolvimentos tecnológicos ou novidades interplanetárias, e consideram que a preocupação com a escrita pode prejudicar a história, por outro, críticas internas à FC, feitas pelas mesmas razões, também não são incomuns. $\mathrm{O}$ polonês Stanilaw Lem escreveu romances focados em descobertas científicas e viagens espaciais explorando estilos de escrita e técnicas narrativas que conquistaram tanto os leitores de FC quanto a crítica literária. Lem, contudo, não poupou críticas aos colegas, e repetiu várias vezes que era necessário cuidar mais da escrita e evitar esquemas, ao mesmo tempo em que afirmava que criar novos mundos não era suficiente quando se repetia sempre os mesmos padrões. ${ }^{22}$
22. LEM. The time-travel story and related matters of science fictio structuring, p. 85. 

backwash: 1960-1980, p. 50.
Outro exemplo de crítica interna partiu de Alfred Bester que, apesar de reconhecer que muitos de seus colegas escreviam bem, lamentou que não desenvolvessem histórias de maior qualidade: "Muitos dos autores que praticam ficção científica se revelam em suas obras como [...] pessoas tolas e infantis que encontraram refúgio na ficção científica, onde eles podem estabelecer suas próprias regras arbitrárias sobre a realidade para que elas se apliquem às suas próprias inadequações. ${ }^{23} \mathrm{O}$ texto de Bester foi utilizado por Broderick para ilustrar a crise no gênero que precedeu o movimento New Wave na FC que trouxe um sopro inovador ao gênero.

Os autores da New Wave foram jovens interessados pela literatura beat. Suas obras foram as primeiras do ramo da FC com influência modernista expressa pelo uso de técnicas narrativas como o fluxo de consciência ou pela abordagem de questões da psicologia. Acima de tudo, eles procuraram abordar as hipóteses tecnológicas e futuristas se distanciando de padrões pré-estabelecidos, liberando a FC dos limites impostos pela "literatura de gênero". A crítica feita na entrevista concedida por Scholz, que inspirou Sterling a cunhar o termo slipstream, se refere especialmente ao fato de que, passada a New Wave, praticamente não foi dada continuidade a esse tipo de escrita, o que, segundo Scholz, teria sido suficiente para que a FC finalmente passasse a ser recebida com maior respeito pela crítica. Scholz também comenta que os melhores livros que leu nos últimos tempos - Atwood, DeLillo etc. - não foram vencedores dos principais prêmios de FC, como o "Hugo" e o "Nebula". O problema apontado é duplo: não apenas ele indica uma crise e a necessidade de renovação dentro do gênero para que ele não acabe perdendo, de uma vez, a importância, mas também indica a deficiência ou a ausência de um intercâmbio entre as partes; os melhores livros sobre assuntos científico-ficcionais não venceram os principais prêmios ${ }^{24} \mathrm{e}$ isso talvez pudesse ser justificado por terem sido escritos por autores que não eram parte do "clube". ${ }^{25}$

\section{SLIPSTREAM}

Sterling afirma não ter a intenç̃o de reformar a FC na direção da "literatura" através do slipstream, mesmo porque grande parte dos autores citados por ele não fazem parte do circuito de FC. O próprio nome "slipstream" é uma brincadeira com isso. Embora a palavra exista em língua inglesa e signifique "cone de aspiração", Sterling cria aqui um neologismo com as palavras "slip" (escorregar) e "mainstream", indicando a mistura da FC (e a fantasia) com a chamada literatura "mainstream".

Ao procurar definir as características do novo gênero, Sterling aponta que essa não seria uma "categoria comercialmente bem sucedida", porque "autores de slipstream têm
24. "Hugo" e "Nebula" são os principais prêmios de FC, outorgados por organizações de autores do genero. Enquanto o "Nebula" apenas não premiou nenhum autor que seja de fora do grupo, mas chegou a nominá-los (exemplos săo Thomas Pynchon com $O$ arco-íris da gravidade e Margaret Atwood com $O$ diário da aia), o "Hugo", prêmio de maior importância, sequer nom

25. O problema, evidentemente, é uma via de mão dupla. Na Alemanha, Corpus delicti (2009) domear ao Prêmio Kurd-Laßwitz porém a nomeação foi rejeitada pla autora que afirma não ver o seu trabalho como FC. Rejeição semelhante foi observada nas afirmações iniciais de Atwood, que defendia que seus livros eram ficção especulativa e não FC. A justificativa de Atwood era que os livros de FC descenderiam de H.G. Wells por tratarem de coisas impossíveis, enquanto que os de ficção especulativa viriam da linhagem de Jules Verne e abordariam acontecimentos que são possiveis, mas que ainda não se realizaram. $>>$

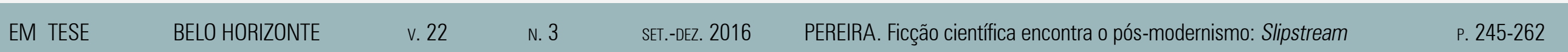

\section{Crítica Literária, outras Artes e Mídias}


25. >>> Desnecessário dizer que o argumento de Atwood era sem fundamento: ambos os autores descreveram mundos irreais e fatos que não passaram a existir da forma descrita. Além disso, o conceito de "ficçáo especulativa" nasceu dentro da própria FC. El foi desenvolvido por Robert A Heinlein e é o que se pode chamar de um termo "guarda-chuva" que abrange desde a FC até a fantasia. Essa terminologia, assim como o fato de que Atwood confundia os suas falas - era frequentasia en suas falas - ra frequente que ela de $\mathrm{FC}-$, foi algo que lhe foi elucidado por Le Guin, de forma que Atwood acabou por se afastar da discussão sobre a classificação da FC. O desenvolvimento dessa polêmica pode ser observado na publicação de ensaios que Atwood dedicou à FC e à Le Guin como forma de sinalizar a sua boa vontade: In other Worlds. SF and the Human Imagination (2011).

\section{STERLING. Slipstream.}

27. FEINKL. Introduction, p. iv-v. que trabalhar fora das infraestruturas confortáveis de revistas de gênero, crítica especializada em gênero, e o espírito de lealdade autoral de uma causa de gênero comum." ${ }^{26}$ Com a força que a FC tem no mercado editorial local (EUA), possibilidade de criar histórias fora de padrões pré-estabelecidos parece estranha e apresenta dificuldades com as quais os autores de FC não estão familiarizados. Mesmo sendo uma ideia estranha ao grupo, ela parece ter a capacidade de oxigenar as criações e ideias no ramo. Esse aspecto da definição, inclusive, foi abraçado por outros escritores que organizaram uma fundação denominada de "interstitial", que se propõe a reunir escritores de "literatura de gênero" que estejam dispostos a ignorar expectativas de editores e leitores, e quebrar padrões através da mistura de estilos de "literaturas de gênero" distintas. ${ }^{27}$

O ensaio de Sterling, infelizmente, não prima pela clareza É possível afirmar que sua explicação tautológica parte do princípio explicativo de Knight, ou seja, que "slipstream é aquilo para o que apontamos quando dizemos isso”. Sterling faz pouco uso de descrições ou enumerações de características, e baseia a definição do suposto gênero principalmente na listagem de 135 obras ao final do ensaio. A lista de Sterling, entretanto, mais confunde do que esclarece. Boa parte das obras sequer se encaixa nos pré-requisitos apontados pelo próprio autor: literatura não-realista, pós-moderna e que cause a sensação de estranheza. Entre elas está, por exemplo, Homo faber de Max Frisch, que pode causar certa estranheza, mas isso não tem nenhuma relação com novas tecnologias ou efeitos sobrenaturais, e sim com a proposta de pensar uma tragédia grega nos dias de hoje.

A principal complicação está, contudo, no fato de Sterling não ter limitado a sua hipótese de gênero à FC e tê-la estendido à fantasia. O problema jaz no fato de que os círculos de leitores/estudiosos de FC e fantasia rejeitam o conceito de literatura fantástica. Para eles, qualquer tipo de literatura que não seja "realista" é definida como fantasia, sem a necessidade de distinção. O fantástico é entendido como uma definição que serve apenas para qualificar as obras de acordo com uma escala de valor, na qual a fantasia seria preterida e relegada a um patamar mais baixo. Assim, ignorando o conceito e as discussões que são feitas sobre o fantástico no âmbito da crítica acadêmica, os leitores de FC/fantasia acabaram por rotular obras fantásticas como slipstream. Alguns exemplos frequentes em discussões que procuram definir o que seria o slipstream são: Franz Kafka, Jorge Luis Borges, Gabriel Garcia Marquez e Haruki Murakami. O interessante é notar que, apesar de o fandom da FC/fantasia negar que o fantástico seja um estilo ou modo literário diferente da fantasia, parte deles compreende a necessidade de classificar

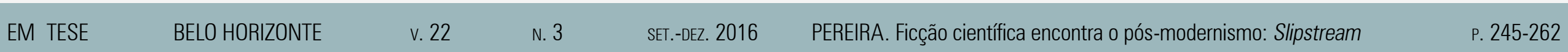

Crítica Literária, outras Artes e Mídias 
28. TODOROV. Introdução à literatura fantástica, p. 30.

29. TODOROV. Introdução à literatura fantástica, p. 47-48.

30. CESERANI. O fantástico, p. 55 essas obras em outra categoria, e assim o fazem quando podem aplicar um termo nascido na FC.

Quando os estudiosos de fantasia se opõem à separação da fantasia e do fantástico, costumam citar apenas Tzvetan Todorov, sem levar em conta outros estudos da área que têm suas próprias objeções a essa teoria. Em Introdução à literatura fantástica, Todorov descreve o fantástico como uma literatura definida pela recepção do leitor, onde deve ocorrer "um acontecimento que não pode ser explicado pelas leis deste mundo familiar". ${ }^{28}$ Para Todorov, o "fantástico puro" tem uma breve duração; ele dura tanto quanto durar "a hesitação comum ao leitor e à personagem, que devem decidir se o que percebem depende ou não da 'realidade', tal qua existe na opinião comum". ${ }^{29}$ No momento em que se decide por uma solução ou outra, o modo fantástico seria abandonado. Quando a hesitação ocorre devido a um acontecimento material que desafie a razão, a narrativa é classificada como "fantástico-maravilhoso", enquanto que quando ela é justificada apenas pelos sentimentos e a percepção da personagem, mas não por fatores sobrenaturais, ela é classificada como "fantástico-estranho". Remo Ceserani critica Todorov pelo excesso de especificidade que reduz o fantástico a "um momento quase virtual". ${ }^{30}$ Ceserani cita Lucio Lugnani para comentar o problema das classificações de estranho e de maravilhoso segundo Todorov. Lugnani problematiza essa divisão porque não se tratam de categorias simétricas, homogêneas e nem excludentes. $\mathrm{O}$ maravilhoso, segundo Lugnani, é uma variedade constituída por um patrimônio milenar, enquanto que o estranho seria algo recente, desenvolvido a partir do Iluminismo. ${ }^{31}$ Dessa Forma, Lugnani sugere que o estranho, o fantástico e o maravilhoso deveriam ser categorias completamente distintas, onde o primeiro daria conta da narração de uma supressão aparente do real, o segundo de uma supressão não redutível do real e, por fim, o terceiro, de uma supressão paradigmática do real.

Já a crítica de David Roas a Todorov se deve ao fato de sua definição ser muito centrada nos séculos XVIII e XIX e não se aprofundar mais na literatura fantástica do século XX. A hesitação que ocorre nas narrativas descritas por Todorov, muitas vezes causada apenas pela percepção do protagonista de tais histórias (usualmente desenvolvidas a partir do olhar de um narrador homodiegético), é característica do romantismo, e não dá conta de narrativas posteriores, como A metamorfose de Kafka, citada furtivamente pelo próprio Todorov. Roas inicialmente chama essa nova fase de "neofantástico", demarcando a diferença entre a descrição feita por Todorov e essa nova literatura na qual, apesar da presença de elementos que o leitor identifica como "sobrenaturais" ou maravilhosos, não ocorre nenhuma vacilação por parte das personagens ao vivenciar fatos incríveis. Mais

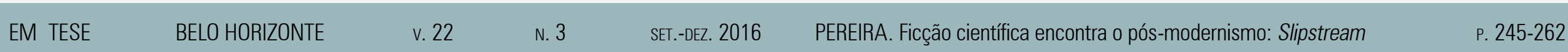

\section{Crítica Literária, outras Artes e Mídias}


32. ROAS. A ameaça do fantástico, p. 73 adiante, Roas irá deixar o conceito de "neofantástico", ao afirmar que " $[\mathrm{t}$ ] anto o fantástico tradicional como o fantástico contemporâneo se baseiam em uma mesma ideia: produzir a incerteza diante do real". ${ }^{32} \mathrm{Ou}$ seja, a definição do fantástico se dá "a partir de duas instâncias fundamentais: o real e o impossível (ou seus sinônimos: sobrenatural, irreal, anormal etc.)".33

Apesar de não levarem as considerações acima expostas em conta, os estudiosos e leitores de fantasia, ao saírem à busca de obras que se encaixem na descrição de slipstream dada por Sterling, ou seja, uma literatura que causa estranheza, acabam chegando à literatura fantástica e são obrigados a reconhecer que se trata de uma narrativa diferente $\mathrm{da}$ fantasia. A hesitação causada pelo contraste de fatos sobrenaturais ou anormais estarem sendo descritos em um mundo que reconhecemos como sendo o nosso mundo "real" é lida pelos defensores do slipstream como a "estranheza" que deveria ser causada no leitor. Esse lapso foi notado, por exemplo, por Farah Mendlesohn em seu livro, Rhetorics of fantasy (2008), mas isso não fez com que ela cedesse a aceitar o fantástico como uma definição diferente da fantasia, do mesmo jeito que ela rejeita a própria definição de slipstream. Para Mendlesohn, o que há são diferentes tipos de percepção do extraordinário, da fantasia. O notório é que, por tratar exclusivamente do mundo da fantasia, e tomar sempre o mundo maravilhoso como ponto de partida, as obras definidas por Todorov como fantástico-estranho, onde o fato que aparenta ser sobrenatural se justifica como resultado de acontecimentos naturais, acabam em uma espécie de ponto cego, fora do recorte proposto. Quanto ao slipstream, ele se resumiria à quebra da expectativa do leitor causada pelo uso de "técnicas narrativas" fora do gênero ao qual elas pertencem, sendo que os elementos sobrenaturais ou científico-ficcionais (novum) são o que ela chama de "técnicas", e a estranheza seria causada pelo uso delas por escritores que não são familiares à FC e à fantasia e, dessa forma, não seguem regras pré-concebidas pela "literatura de gênero".

Está claro que toda a confusão entre o fantástico e o slipstream já seria suficiente para desqualificar a proposta de Sterling, mas ainda restam os textos que discutem o slipstream pelo viés da FC, de forma que será dado prosseguimento às ponderações sobre o suposto gênero.

O exemplo mais recorrente do que seria slipstream é Atlas de nuvens de David Mitchell. Escrito por um autor contemporâneo considerado de alto escalão, o livro é um pastiche de diferentes gêneros e apresenta duas linhas narrativas de fundo científico-ficcional: numa delas, o novum é a clonagem humana, na outra, a Terra futura em um estado pós-apocalíptico. Mendlesohn introduz as considerações sobre Atlas de nuvens com as seguintes palavras: 
34. MENDLESOHN. Rhetorics of fantasy, p. 241.

35. Deve-se notar que quando Mendlesohn escreve sobre gênero, ela trata claramente do funcionamento do que aqui estamos chamando de "literatura de gênero".

36. MENDLESOHN. Rhetorics of fantasy, p. 241
Nessa seção, é importante estar alerta de que todos os livros que discuto são livros dos quais eu gosto. Meu argumento, entretanto, é que as estratégias narrativas das quais eles se ocupam - tanto no nível do enredo quanto da retórica - posicionam o leitor de maneira diferente da fantasia limiar; apesa de eles frequentemente empregarem os tropos da fantasia (ou da ficção científica), eles o fazem com uma intenção muito diferente, e atentos a um conjunto diferente de expectativas do leitor. Em outras palavras, eles não estão falando comigo. ${ }^{34}$ (itálico do original)

Como é costume nas obras teóricas sobre fantasia e FC, Mendlesohn se posiciona claramente dentro do fandom fora do grupo de receptores do restante da literatura. Da forma como é colocado aqui, slipstream seria uma definição que serviria para abraçar aquilo que é chamado por Sawyer como "outsider science fiction". Mendlesohn argumenta aind que "apesar de Mitchell haver utilizado muitos tropos do gênero, ele não está utilizando eles para escrever dentro do gênero, ${ }^{35}$ mas para escrever sobre ele". ${ }^{36}$

De fato, Atlas de nuvens é um experimento com diferentes gêneros literários. O romance conta com seis narrativas que são apresentadas como um livro dentro de outro livro dentro de outro livro, sucessivamente, como em camadas de uma cebola. Nesse quebra-cabeça, Mitchell apresenta histórias de abuso de poder e opressão em diferentes contextos e épocas, começando com a exploração de aborígenes neozelandeses pelos colonizadores, passando pelo preconceito contra homossexuais e chegando até a clonagem humana, em um romance que apresenta a eterna repetição de erros. Além de ambientar as histórias em diferentes épocas, Mitchell imita diferentes estilos de escrita e tipos de "literatura de gênero". Assim, o romance começa com um diário, depois passa a um romance epistolar, um romance policial, um livro cômico, uma distopia e, por fim, uma história de FC em um tempo distante. Como as duas histórias nucleares se passam no futuro, ambas apresentam elementos que podemos identificar como nova, mas o livro não é dedicado a FC em especial. Sua força está justamente na mistura de variados gêneros e no talento do autor para imitá-los.

Atlas de nuvens não ficou famoso por suas características de FC, mas pela estrutura narrativa. Foi o seu estilo inovador que convenceu os críticos de seu valor, e que atraiu os fãs do slipstream: além de apresentar elementos científico-ficcionais, o romance de Mitchell é inovador e, portanto, "estranho", exatamente como o slipstream deve ser.

Essa "estranheza", no caso de autores que eles julgam ser "mainstream", poderia se limitar ao fato de serem obras com uma ênfase maior nos protagonistas do que nos desenvolvimentos tecnológicos, mas a seleção feita pelo fandom é muito

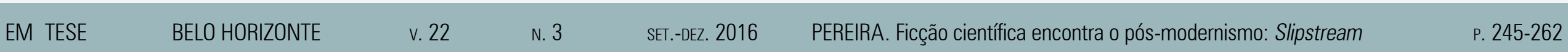


37. KELLY; KESSEL. Feeling very strange, $p . x i$.

38. Sterling afirma em um ensaio publicado em 2011 que "se o slipstream tivesse feito o que escrevi aquele artigo, haveria na realidade, estantes na [loja] Borders e Barnes \& Noble com os dizeres slipstream nelas. Você poderia ir até elas e comprar esses romances fantásticos e antirrealistas com uma sensibilidade pós-moderna, e eles teriam os seus próprios prêmios, seus próprios pequenos fanzines $e$ convenções [...]. >>>

39. KELLY; KESSEL. Feeling very strange, $p$. ix.

40. KELLY; KESSEL. Feeling very strange, p. ix. mais abrangente do que isso. A edição mais importante sobre o assunto é a antologia de contos Feeling very strange, organizada por James Patrick Kelly e John Kessel. O livro é introduzido por um ensaio que busca explicar o que seria esse novo gênero - um dos textos mais claros e lúcidos sobre o assunto -, mas, como em outros casos, a argumentação se baseia fortemente na listagem de títulos, aqui representados pela própria antologia. A seleção traz alguns nomes que têm aceitação da crítica literária "mainstream", mas está especialmente voltada para autores do fandom, como Sterling e Theodora Goss.

Fazendo referência a Suvin, eles afirmam que: "Slipstream é a literatura da dissonância cognitiva e do estranhamento triunfante." ${ }^{37}$ (itálico do original) O jogo de palavras aponta para o fato de que, ao contrário da FC tradicional, não há nenhuma necessidade de justificar os elementos desviantes de uma representação "realista" do mundo, pelo contrário, isso até é desejável para que se provoque o efeito de "estranheza". Apesar de Sterling ter pensado no conceito como uma forma de "categoria de marketing", ${ }^{38}$ Kelly e Kessel acreditam que não se trata de um modo de publicação, mas de um modo de escrita, ${ }^{39}$ cuja classificação como "categoria de publicação apenas tem sentido para aqueles que vêm do lado da divisão que se ocupa com literatura de gênero". ${ }^{40}$

De forma bem colocada, os autores relembram o anteriormente citado movimento da New Wave que revolucionou
FC ao utilizar técnicas de escrita modernas como narrativa fragmentada ou "realismo" psicológico. Tais técnicas, contudo, só eram novas para o público da FC, e já eram utilizadas na literatura há mais de meia década. Infelizmente, não houve uma continuidade que conduzisse a FC à escrita pós-moderna. O pós-modernismo na $\mathrm{FC}$ foi representado principalmente pela estética cyberpunk, mas não pelas técnicas narrativas. O slipstream, portanto, seria principalmente marcado pelo fato de ser "ludicamente pós-moderno", ${ }^{41}$ ou seja, pela introdução de características narrativas pós-modernas na escrita da FC. Essa é uma das justificativas da dupla, devido à qual a "categoria publicitária" só serviria ao fandom: esse tipo de escrita não seria mais nenhuma novidade para a literatura em geral.

Mesmo a divisão entre a "literatura de gênero" e a "alta" literatura, mencionada por Kelly e Kessel, já não é mais tão marcada fora do âmbito do fandom. Em After the great divide, Andreas Huyssen defende que a acentuada divisão entre "alta" cultura e a cultura de massas seria o que distingue o modernismo do pós-modernismo. Enquanto o modernismo foi marcado pelo surgimento do conceito da indústria cultural, desenvolvido por Adorno no período pós-guerra, e a arte da época teria tido uma forte necessidade de se firmar através da distinção daquilo que se acreditava ser uma categoria mais baixa de arte, o pós-modernismo deu continuidade
38. >>> Essa é a grande força de uma categoria de marketing. Se você está em uma estante de ficção científica, olhando a letra "s", você verá "Stephenson" e "Sturgeon", e pode acabar pegando um dos meus livros por acidente, pensando que eu sou o Theodore ou o Neal. Isso é de um uso comercial considerável para mim. Mas se você está tentando comprar um livro de slipstream, não há a possibilidade de passa de Pynchon para John Calvin Matchelor para Gabriel Garcia Robert Coover. Eles Acker para não estão sugeriria a você que eles têm algo em comum ou que eles têm relevância um para o outro. Isso os prejudica." (STERLING. Slipstream 2)

41. KELLY; KESSEL. Feeling very strange, p. xii.

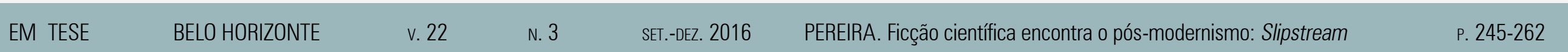

\section{Crítica Literária, outras Artes e Mídias}


a técnicas artísticas desenvolvidas pelo modernismo, mas teria voltado a ser capaz de absorver elementos das culturas populares (que agora incluem a cultura de massa), como sempre foi comum à vanguarda antes que o modernismo despontasse com seus julgamentos sobre a produção de arte em escala industrial. Na verdade, a movimentação percebida por Scholz e Sterling na chamada literatura "mainstream" foi a de escritores pós-modernos colhendo referências em gêneros com os quais escritores modernistas antes evitavam se misturar. Boa parte do que se busca descrever com o slipstream são apenas as consequências do pós-modernismo.

Mesmo com a consciência de que é o pós-modernismo que está em jogo, as descrições do slipstream continuam relacionadas principalmente à sensação de estranheza. Levando-se em consideração a seleção feita para Feeling very strange, é verificado que essa sensação parece ser atingida de diferentes formas. Uma delas é a apresentação do novum inserido em um mundo semelhante ao nosso e no qual as personagens também reagem a esse elemento maravilhoso com estranheza, sem que ele seja devidamente explicado e justificado em algum momento. Esse é o traço distintivo do conto "Light and the Sufferer", de Jonathan Lethem. A história se passa em um mundo que nos é familiar, com o diferencial de que extraterrestres teriam chegado à Terra, sem que ninguém soubesse precisar ao certo o que eles desejam em nosso mundo. A relação das personagens com os alienígenas varia entre naturalidade (a invasão não é mais uma novidade), desconfiança e estranheza, já que até o momento não houve nenhuma comunicação bem sucedida entre as espécies. Assim, o "estranho" neste conto é a falta de explicações sobre o novum, que fica ainda mais acentuada devido ao fato de todo o resto da história correr de uma forma que nos parece "natural". É muito frequente que a estranheza seja causada pelo simples fato de que os acontecimentos descritos não são claramente elucidados pelo narrador. Enquanto "Light and the Sufferer" ainda se diferencia das histórias fantásticas, por sua relação com a FC, outras histórias podem ser descritas como um conto fantástico simples, como "The little magic shop" de Sterling, ou uma simples história de fantasmas, como "The specialist's hat" de Kelly Link. Por fim, há uma série de contos que apresentam características como pastiche, narrativa não-linear, violações de ponto de vista, narrador não-confiável e metaficção.

Inicialmente, Kelly e Kessel falam sobre um modo de escrita que apenas agora está sendo notado pelos fãs de FC. Mas o que o seu livro revela é que o slipstream, além de não ser um gênero novo, acabou se tornando um impulso dentro da FC que incentiva um novo posicionamento frente às técnicas narrativas. Por muito tempo, o fandom de FC se defendeu das acusações de ser um gênero menor 
atacando o estilo de escrita do "mainstream" que "apenas serviria para confundir”. A escritora Gwyneth Jones, por exemplo, defende que a FC evitava as armadilhas do mainstream para não distrair os leitores daquilo que realmente importa. ${ }^{42} \mathrm{O}$ conceito de slipstream marca o momento no qual autores de gênero passam a fazer uso dessas técnicas narrativas, que "apenas serviriam para confundir", de forma a torná-las a própria fonte de entretenimento. Em "You have never been here", M. Rickert desenvolve uma história de FC truncada na qual o protagonista da história é "você", sem deixar claro por onde esse protagonista tem andado ou o que realmente está acontecendo. A função da história, ao contrário de muitas das narrativas de FC, não é de fazer críticas sociais que poderiam correr risco de ser obscurecidas por essa narratividade, como acusa Jones. Rickert apenas brinca com as novas possibilidades narrativas e escreve uma espécie de thriller de FC que não tem mais do que o desejo de divertir.

Ao ler Feeling very strange, fica claro que, além da recusa em aceitar o fantástico como um estilo distinto da fantasia, a definição proposta pelo slipstream tem outro problema fundamental: se basear mais na sensação do estranho do que na descrição detalhada de características que gerariam esse resultado. O entrave mais evidente é o fato de que não há um definidor comum sobre o que será percebido como estranho por todos os leitores. Mesmo nas histórias onde as técnicas narrativas são responsáveis pelo efeito de estranheza, esse efeito pode acabar se perdendo com o tempo. O próprio fato de autores de "literatura de gênero" estarem fazendo uso delas aponta para uma familiarização maior que possivelmente fará com que essas técnicas não sejam mais entendidas como "estranhas" no futuro. Esse processo pode se dar da mesma forma que ocorreu com a montagem de Serguei Eisenstein e o estranhamento de Brecht. Em ambos os casos, as técnicas vanguardistas foram absorvidas pelo público geral: a montagem de Eisenstein hoje em dia é utilizada por produções de Hollywood, e as técnicas de Brecht se esvaziaram do estranhamento obrigando as companhias de teatro a buscar sempre novos meios que sejam capazes de produzir o efeito. Assim, uma descrição das características específicas se faz necessária, pois há grande risco de que essas técnicas percam o efeito de estranheza que seria a característica principal do slipstream.

Mesmo que o termo seja de pouca relevância para os que se encontram fora do círculo da FC, isso não tira a importância dessa movimentação, já que ela incentiva fãs da FC a um posicionamento mais aberto ante a livros que não são escritos por autores especializados e promove a oxigenação da escrita dentro dos limites do gênero da FC. 


\section{DIÁLOGO POSSÍVEL?}

O movimento slipstream poderia ser uma porta para o diálogo entre os especialistas em FC e os críticos de literatura. Infelizmente, a confusão ainda impera nas discussões sobre o tema e ainda há uma tendência à rejeição daqueles que não pertencem ao grupo. Kelly afirma que: "Estou mais interessado em rastrear as pessoas que partem da nossa tradição na jornada através dos gêneros do que nos escritores mainstream que vêm se meter com os nossos tropos." ${ }^{43}$ Kelly parece ressentir, acima de tudo, o descaso que foi feito da FC. Apesar de o chamado "mainstream" não ser tão coeso e unido como parece pressupor o fandom de FC, Kelly não se mostra realmente disposto ao diálogo com o que ele percebe como sendo o "inimigo". À proposta de Lethem de abandonar completamente as barreiras de gênero, Kelly responde:

O ensaio de Jonathan [Lethem] era um experimento mental sobre o que aconteceria se a ficção científica se misturasse com o mainstream. Ele argumentou que seria melhor para todos os envolvidos se não houvesse gêneros. [...]. Nessa utopia literária não haveria FC ou slipstream ouo que mainstream. Nós seríamos todos uma grande família feliz. / Tá bom. Isso vai acontecer mais ou menos no mesmo momento em que um robô virar papa. ${ }^{44}$
A continuidade dessa animosidade é lamentável, mas o processo de absorção da FC pela literatura dificilmente pode ser parado agora: além dos rápidos avanços tecnológicos vivenciados no dia-a-dia, o imaginário da FC já faz parte do cotidiano urbano e a tendência é que esteja cada vez mais presente na literatura contemporânea. Uma trégua seria útil para enriquecer os estudos de ambos os lados, e Kelly deveria convir que um "papa robô" seria altamente desejável para a FC.

\section{REFERÊNCIAS}

Aldiss, Brian W.; Wingrove, David. On the origin of species: Mary Shelley. In: GUNN, James; CANDELARIA, Matthew (ed.) Speculations on speculations: Theories of science fiction. Toronto, Oxford: The Scarecrow Press, 2005 p.163-203.

Atwood, Margaret. In other worlds: SF and the human imagination. New York: Virago, 2011.

BRODERICK, Damien. New wave and backwash: 1960-1980. In JAMES, Edward; MENDLESOHN, Farah (ed.) The Cambridge companion to science fiction. Cambridge: Cambridge University Press, 2003. p. 48-63.

CESERANI, Remo. O fantástico. Trad.: Nilton Cezar Tridapalli. Curitiba: Editora UFPR, 2006

CONOUEST, Robert. Science fiction and literature. In: ROSE, Mark. Science fiction: A collection of critical essays. New Jersey: Prentice-Hall, 1976. p. 30-45. 
FEINKL, Heinz Insu. Introduction. In: SHERMAN, Delia:

GOSS, Theodora (ed.). Interfictions. Boston: Insterstitial Arts

Foundation, 2006. p. i-viii.

Friedrich, Hans Edwin. Science-Fiction. In: LAMPING, Dieter et al. Handbuch der literarischen Gattungen. Stuttgart: Alfred Kröner Verlag, 2009, p. 672-677.

GUNN, James. Foreword. In: JAMES, Edward; MENDLESOHN Farah (ed.) The Cambridge companion to science fiction. Cambridge: Cambridge University Press, 2003 p. IX-X|.

HUYSSEN, Andreas. After the great divide. Indianapolis: Indiana University Press, 1986

Jameson, Frederic. Archaeologies of the future: The desire called utopia and other science fictions. London, New York: Verso, 2005.

KELLY, James Patrik; KESSEL, John. Slipstream, the genre that isn't. In: KELLY, James Patrik; KESSEL, John (ed.) Feeling very strange. San Francisco: Tachyon Publications, 2006. p. vii-xv.

KELLY, James Patrick. Slipstream. In: JAMES, Edward;

MENDLESOHN, Farah (ed.) The Cambridge companion to

science fiction. Cambridge: Cambridge University Press, 2003. p. 343-351.

LEM, Stanislaw. The time-travel story and related matters of science fiction structuring. In: ROSE, Mark. Science fiction: A collection of critical essays. New Jersey: Prentice-Hall, 1976. p. 72-88.
Luckhurst, Roger. The Many Deaths of Science Fiction: A Polemic. In: Science Fiction Studies, vol. 62, n. 21/1, 1994, s.p.

MENDLESOHN, Farah. Rhetorics of fantasy. Middletown, Connecticut: Wesleyan University Press, 2008.

Müller, Eggo. Genre. In: Hügel, Hans-Otto. Handbuch Populäre Kultur. Stuttgart, Weimar: J.B. Metzler, 2003, p. 212-215.

RABKIN, Eric S. Defining science fiction. In: GUNN, James et al. Reading science fiction. Hampshire: Palgrave Macmillan, 2009. p. 15-23.

ROAS, David. A ameaça do fantástico. Trad.: Julián Fuks. São Paulo: Editora Unesp, 2014.

ROBERTS, Adam. Science fiction. New York, London: Routledge, 2000.

SAWYER, Andy. Kazuo Ishiguro's Never let me go and "outsider science fiction". In: GROES, Sebastian; LEWIS, Barry (ed.). Kazuo Ishiguro: New critical visions of the novels. Hampshire: Palgrave Macmillan, 2011. p. 236-246.

SHIPPEY, Tom. Preface: Learning to read science fiction. In: SHIPPEY, Tom. (ed.) Fictional space: Essays on contemporary science fiction. Atlantic Highlands: Humanities Press, 1991. p. $1-33$

STERLING, Bruce. Slipstream. In: SF Eye, EUA, n. 5, 1989. Disponível em https://w2.eff.org/Misc/Publications/Bruce Sterling/Catscan columns/catscan.05 Acesso em 13 jan. 2013. 
Slipstream 2. In: Science fiction, EUA, vol. 38, n. 1

mar/2011. Disponível em http://www.depauw.edu/sfs/abstracts/

a113.htm\#sterling. Acesso em 08 jun. 2014.

SUVIN, Darko. Estrangement and cognition. In: GUNN, James:

CANDELARIA, Matthew (ed.) Speculations on speculations:

Theories of science fiction. Toronto, Oxford: The Scarecrow

Press, 2005. p. 23-36.

Suvin, Darko. Metamorphoses of Science Fiction. On the

Poetics and History of a Literary Genre. New Haven, London:

Yale University Press, 1979.

TODOROV, Tzvetan. Introdução à literatura fantástica. Trad.

Maria Castello. 4. ed. São Paulo: Perspectiva, 2010. 